\title{
Ethylene Glycol Electro-Oxidation on Platinum-Free Surfaces: How the Composition of PdRuRh Surfaces Influences the Catalysis
}

\author{
Gisele A. B. Mello, Pedro H. B. Fernandes, Martha Janete de Giz and \\ Giuseppe A. Camara* \\ Instituto de Química, Universidade Federal de Mato Grosso do Sul, C.P. 549, \\ 79070-900 Campo Grande-MS, Brazil
}

\begin{abstract}
In this work we performed electrochemical (cyclic voltammetry and chronoamperommetry) and spectroelectrochemical studies (in situ Fourier transform infrared (FTIR)) in PdRuRh electrodeposits in acidic media in presence of ethylene glycol $\left(0.5,1.0\right.$ and $\left.2.0 \mathrm{~mol} \mathrm{~L}^{-1}\right)$. The electrochemical results show that the ethylene glycol oxidation is sensitive to the composition of the catalysts, being PdRuRh 74:09:17 the composition which presents the best catalytic activity. Also, conversely to Pt, these surfaces do not present a self-inhibitory effect when the EG concentration is increased. FTIR results indicate a complex reaction mechanism under these conditions, where glycolic acid, oxalic acid, formic acid and $\mathrm{CO}_{2}$ are detected as electro-oxidation products. The best catalytic activity observed for $\mathrm{PdRuRh}$ 74:09:17 can be understood in terms of a higher selectivity towards the production of $\mathrm{CO}_{2}$, which is the oxidation pathway that involves the release of the major number of electrons.
\end{abstract}

Keywords: electrocatalysis, ethylene glycol electro-oxidation, palladium-ruthenium-rhodium, in situ FTIR, self-inhibitory effect, ethylene glycol pathways

\section{Introduction}

Besides the limited resources, environmental issues have been stimulated researchers around the world to search for new fuels in substitution to fossil fuels. In this subject, over recent years ethylene glycol (EG) has attracted increasing attention, as a possible candidate for use in direct alcohol fuel cells (DAFC) once it is a biorenewable, ${ }^{1}$ highly soluble molecule. ${ }^{2,3}$ Moreover, its low degree of toxicity, low flammability, high melting point, high energy density, high reactivity and high theoretical energy efficiency are characteristics that qualify it as a candidate for DAFC. ${ }^{2-4} \mathrm{EG}$ is an alcohol similar to ethanol (because it possesses a $\mathrm{C}-\mathrm{C}$ bond in its structure), and is also similar to glycerol, once each carbon have a hydroxyl group attached to it. Thus, the study of its electro-oxidation can provide important information that could be applied to other alcohols of strategic interest in electrocatalysis. Therefore, many studies are devoted to investigation of adsorption and electro-oxidation steps of ethylene glycol on Pt electrodes and metallic combinations using $\mathrm{Pt}$ as a major component. ${ }^{5-12}$

*e-mail: giuseppe.silva@ufms.br
The complete electrochemical oxidation of ethylene glycol (EG) to $\mathrm{CO}_{2}$ in acid media is a process which involves 10 electrons per molecule, as depicts reaction 1 :

$\mathrm{HO}-\mathrm{CH}_{2}-\mathrm{CH}_{2}-\mathrm{OH}+2 \mathrm{H}_{2} \mathrm{O} \rightarrow 2 \mathrm{CO}_{2}+10 \mathrm{H}^{+}+10 \mathrm{e}^{-}$

Similarly to what happens with analogous alcohols (as ethanol and glycerol), the EG electro-oxidation takes place through multiple pathways on Pt or Pt-based surfaces in acid media. These parallel pathways culminate in the formation of several substances, such as glycolaldehyde, glyoxal, glycolic acid, glyoxilic acid, oxalic acid and others. ${ }^{4,7,13}$ Also, the occurrence of multiple oxidation pathways seriously compromises the energy efficiency of the reaction, since each product of incomplete oxidation provides fewer electrons to the surface than that would be expected for the formation of $\mathrm{CO}_{2}$. There is yet another detrimental aspect: the surface of pure $\mathrm{Pt}$ is easily poisoned by some of these partially oxidized species (as $\mathrm{CO}_{\text {ads }}$ ) formed during the oxidation of the alcohol at the anode of a fuel cell, which strongly impact the ability of the system to generate electrical work. ${ }^{14,15}$

Apart from the occurrence of parallel oxidation pathways, an important drawback for the scaling up of 
fuel cell technology is (still) the high costs of the catalysts, once they are based on Pt, which is a scarce resource. These experimental difficulties have inspired some authors to propose the use of Palladium (Pd) to replace $\mathrm{Pt}$, and this substitution is justified by the facts that Pd costs a fraction of Pt price (30-40\%) and is around 200 times more abundant on Earth. ${ }^{16}$ Besides that, their electronic properties are similar to Pt, which allows the adsorption of molecules. However, the mere substitution of Pt by Pd does not solve all the technological limitations already mentioned, as shown by Wang et al. ${ }^{17}$ These authors investigated the EG electro-oxidation on Pd surfaces in a wide range of pHs. ${ }^{17}$ According to the authors, Pd exhibits good catalytic activity in alkaline solutions, while higher potentials are required for the formation of $\mathrm{CO}_{2}$ in acid medium. ${ }^{17} \mathrm{~A}$ major limitation of this catalyst is its inability to break the carbon chain of the alcohol, which creates products partially oxidized of intact chain and undertakes energy efficiency of the system. ${ }^{17}$

Based on that, it is necessary to develop catalysts that can act as multifunctional surfaces, whose combination of materials is able to promote $(i)$ the adsorption of molecules on their surface; (ii) the breaking of $\mathrm{C}-\mathrm{C}$ bonds and (iii) oxidation of molecular fragments at low overpotentials. In this context, this paper proposes the use of ternary catalysts based on Pd-Ru-Rh in different atomic compositions. The use of Ru is justified by its oxophilic character that allows this metal to form oxygen species (from adsorbed water) at low potentials, compared to Pt and Pd. ${ }^{18-20}$ Also, theoretical studies performed on Ru-based surfaces have demonstrated that the chemisorption energies of species as $\mathrm{CO}, \mathrm{H}$ and $\mathrm{O}$ are very sensitive to the strain degree of the lattices ${ }^{21}$ and to the alloying degree of $\mathrm{Ru}-\mathrm{Pd}$ surfaces. ${ }^{22}$ On the other hand, $\mathrm{Rh}$ is known to have the ability to break $\mathrm{C}-\mathrm{C}$ bonds, as already shown for the electro-oxidation of acetaldehyde. ${ }^{23,24}$ In this context, several spectroelectrochemical studies address the electrooxidation of EG in the past few years, ${ }^{25-27}$ but the use of ternary catalysts $\mathrm{Pd}-\mathrm{Ru}-\mathrm{Rh}$ is unprecedented in the literature.

\section{Experimental}

Solutions were prepared with Milli-Q water $(18.2 \mathrm{M} \Omega \mathrm{cm}), \mathrm{HClO}_{4} 0.1 \mathrm{~mol} \mathrm{~L}^{-1}$ and ethylene glycol. Before measurements solutions were purged with $\mathrm{N}_{2}$. All the experiments were performed at room temperature $\left(25.0 \pm 1.0^{\circ} \mathrm{C}\right)$. The counter electrode was a platinum sheet and all the potentials were measured against a reversible hydrogen electrode (RHE) in the same electrolyte.

The electrodeposits were prepared by electrochemical reduction of $\mathrm{Pd}^{2+}, \mathrm{Ru}^{3+}$ and $\mathrm{Rh}^{3+}$, at different atomic compositions obtained from $\mathrm{PdCl}_{2}, \mathrm{RuCl}_{3}$ and $\mathrm{RhCl}_{3}$ aqueous solutions in $\mathrm{HClO}_{4} 0.1 \mathrm{~mol} \mathrm{~L}-1$. PdRuRh catalysts were electrodeposited on a polished gold disk at $0.08 \mathrm{~V}$ vs. RHE during $10 \mathrm{~min}$. Pd was kept as the major component (66-74 at.\%), while the composition of $\mathrm{Ru}$ and $\mathrm{Rh}$ was varied from 03:31 to 24:06. The compositions presented here were estimated by energy dispersive X-ray spectroscopy (EDX), performed on a Noran System Six (Thermo Scientific) electron microscope. The experiments are performed at an accelerate voltage of $20.0 \mathrm{kV}$ during 100 seconds, in an angle of 35.0 degrees. Three points have been acquired to obtain the elemental atomic percentages (i.e., corresponding to $\mathrm{Pd} \mathrm{L} \alpha, \mathrm{Ru} \mathrm{K} \alpha$ and $\mathrm{Rh} \mathrm{L} \alpha$ ), and then calculate the average composition. Overall, the atomic compositions of the different points collected in the same sample were virtually identical to each other, suggesting a very homogeneous distribution of $\mathrm{Pd}, \mathrm{Ru}$ and $\mathrm{Rh}$ co-deposits over the surface.

Once obtained, the electrocatalysts were submitted to cyclic voltammetry in $\mathrm{HClO}_{4} 0.1 \mathrm{~mol} \mathrm{~L}^{-1}$ in a potential range of $0.1-0.8 \mathrm{~V} v s$. RHE at $0.02 \mathrm{~V} \mathrm{~s}^{-1}$ for electrochemical characterization. For the estimation of the real surface area the electrodeposits were saturated with $\mathrm{CO}$ by bubbling the gas during $10 \mathrm{~min}$ at $0.05 \mathrm{~V}$. The excess of $\mathrm{CO}$ was then eliminated from the electrochemical cell by purging the solution with pure $\mathrm{N}_{2}$ for $15 \mathrm{~min}$. Afterwards, two consecutive cyclic voltammograms were recorded at $0.02 \mathrm{~V} \mathrm{~s}^{-1}$ in the potential range of 0.05-0.8 V. The first cycle provided the charge of $\mathrm{CO}$ oxidation, while the second one was taken to check the recovering of the original voltammetric profile. Based on this procedure, we estimate similar roughness for all surfaces (among 50 and 66), hence the influence of the roughness factor was not taken into account in the present study. For the electro-oxidation of ethylene glycol the potential was kept at $0.1 \mathrm{~V}$ and the alcohol was admitted into the cell at concentrations of $0.5,1.0$ and $2.0 \mathrm{~mol} \mathrm{~L}^{-1}$ and cyclic voltammetry $\left(0.1-0.8 \mathrm{~V}\right.$ at $\left.0.02 \mathrm{~V} \mathrm{~s}^{-1}\right)$ was performed. Afterwards, the electrodes were kept at $0.1 \mathrm{~V}$ and a potential step to $0.6 \mathrm{~V}$ was applied, being the current-time curves registered for $20 \mathrm{~min}$ to evaluate the electrocatalytic activity of these materials in stationary conditions.

In situ Fourier transform infrared (FTIR) measurements were performed in a FTIR spectrometer (Hartmann \& Braun, model MB-100) coupled to a MCT detector in presence of 0.5 or $2.0 \mathrm{~mol} \mathrm{~L}^{-1}$ ethylene glycol. The electrochemical IR cell was fitted with a $\mathrm{CaF}_{2}$ planar window. Major details about the cell are described elsewhere. ${ }^{28}$

Before each experiment, the working electrode was dipped in hot $\mathrm{H}_{2} \mathrm{SO}_{4}$ and washed with Milli-Q water in abundance. 


\section{Results and Discussion}

First, we proceed to the electrochemical characterization on PdRuRh electrodeposits in acid media. Figure 1 shows the cyclic voltammetries of PdRuRh electrodeposits in $0.1 \mathrm{~mol} \mathrm{~L}^{-1} \mathrm{HClO}_{4}$. The voltammetric features are qualitatively similar for all catalysts, but a deeper look shows that the currents in the hydrogen region $(0.1-0.35 \mathrm{~V})$ are dependent on the composition of the catalyst. Namely, as the surface is enriched with Ru the hydrogen oxidation currents increase. These data are in line with those observed for Pt-Ru-Rh catalysts. ${ }^{23}$ Furthermore, as the catalyst is enriched by $\mathrm{Ru}$ the currents associated to the reduction of oxides (the ill-defined cathodic waves at ca. $0.6 \mathrm{~V}$ ) become less prominent while the currents in the double layer region grow. Indeed, when the Rh content increases, there is a displacement of the currents relative to the reduction of surface oxides towards lower potentials. This effect is discussed in the literature as a consequence of the fact that the oxides of rhodium are very stable and need low potentials to be reduced. ${ }^{24}$

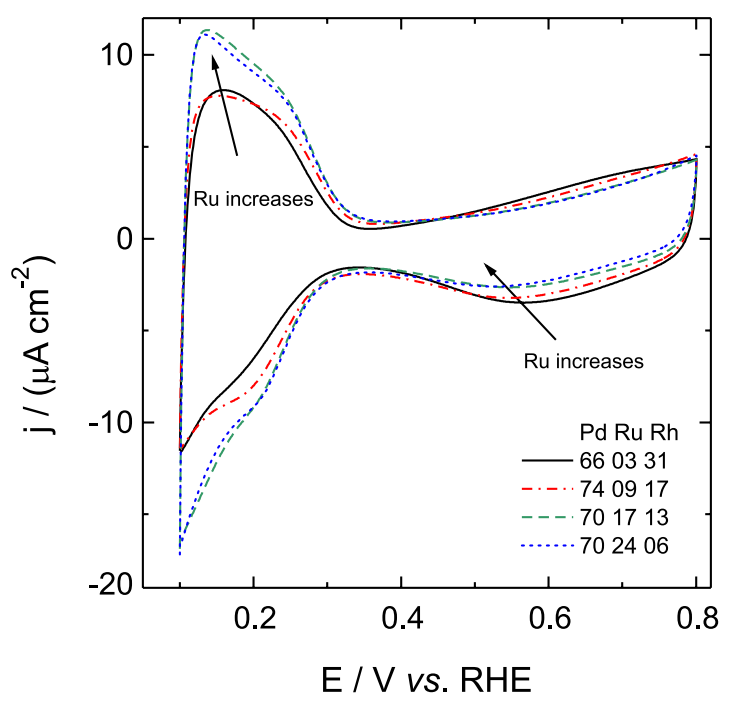

Figure 1. Cyclic voltammograms of PdRuRh electrodeposits in $0.1 \mathrm{~mol} \mathrm{~L}^{-1}$ $\mathrm{HClO}_{4}$ at $0.02 \mathrm{~V} \mathrm{~s}^{-1}$. Real atomic compositions are indicated in the figure.

After electrochemistry characterization in $0.1 \mathrm{~mol} \mathrm{~L}^{-1}$ $\mathrm{HClO}_{4}$, we performed cyclic voltammetries in presence of ethylene glycol $\left(0.5,1.0\right.$ and $\left.2.0 \mathrm{~mol} \mathrm{~L}^{-1}\right)$. The cyclic voltammograms obtained for four compositions are depicted in Figure 2. For all compositions the onset potential is lower than the observed for Pd and is barely dependent on the EG concentration. ${ }^{17}$ However, the beginning of oxidation depends on PdRuRh composition: the EG oxidation started at ca. $0.49 \mathrm{~V}$ on PdRuRh (70:24:06), ca. $0.50 \mathrm{~V}$ on PdRuRh (70:17:13), while EG is oxidized at ca. $0.51 \mathrm{~V}$ on PdRuRh (74:09:17), and at ca. 0.6 V on PdRuRh (66:03:31). As a whole, the results suggest that $\mathrm{Ru}$ atoms favors the reaction, anticipating the EG oxidation.

Based on the fact that the profiles obtained are almost independent on the concentration (Figure 2), the profiles obtained only in $0.5 \mathrm{~mol} \mathrm{~L}^{-1} \mathrm{EG}$ are displayed in Figure 3, for purposes of a better comparison among the compositions investigated. The voltammograms show similar features for all PdRuRh electrodeposits. However, it can be noted a progressive decrease in the currents in the hydrogen-region while the Ru content decreases. Also, the EG oxidation currents grow and reach their maximum values for PdRuRh 74:09:17, followed by the loss of activity for PdRuRh 63:03:31. This intriguing behavior may anticipate a compromise between the ability of $\mathrm{Rh}$ to break carbon chains and the oxophilic character of $\mathrm{Ru}$ atoms. This issue will be resumed later during the discussion of FTIR results.

Aiming to estimate the catalytic response of PdRuRh electrodeposits as a function of the composition we perform a series of chronoamperometric experiments in presence of EG. For this, the working electrode was kept polarized at $0.1 \mathrm{~V}$ in a solution containing $0.1 \mathrm{~mol} \mathrm{~L}^{-1} \mathrm{HClO}_{4}+\mathrm{EG}$ $\left(0.5,1.0\right.$ and $\left.2.0 \mathrm{~mol} \mathrm{~L}^{-1}\right)$. Then, the potential was stepped to $0.6 \mathrm{~V}$ and the electrode remained in this potential for $1200 \mathrm{~s}$, while current-time $(i-t)$ curves were obtained. This potential was chosen because it is in a range of the voltammograms where EG oxidation currents are noticed, as showed in Figure 2. For each composition, three identical experiments were performed.

The current densities for EG electro-oxidation measured after $1200 \mathrm{~s}$ are plotted as a function of Ru / atomic \% at in Figure 4 . The dashed lines are used just to guide the reader and do not represent any mathematical adjustment.

It is indubitable that PdRuRh 74:09:17 (represented in "Ru / atomic \%" graph by value 09) presents the higher current densities for the three EG concentrations investigated. These data corroborate the voltammetric behavior shown in Figure 3 and indicate that PdRuRh 74:09:17 is the most active composition for EG electrooxidation among those investigated.

Another important aspect of Figure 4 is that overall the currents grow with EG concentration (except for PdRuRh 66:03:31, first points on the left). According to previous results for ethano ${ }^{29}$ and glycerol electrooxidation, ${ }^{30}$ when concentrations of these alcohols exceed $0.1 \mathrm{~mol} \mathrm{~L}^{-1}$ in presence of Pt, surface sites become replete of adsorbates stemmed from the alcohol. This surface excess, in turn, hinders the formation of oxygenated species required for the steps of oxidation, seriously compromising the energy efficiency of the system. In the present work we do not observe this phenomenon (i.e., the currents increase with 

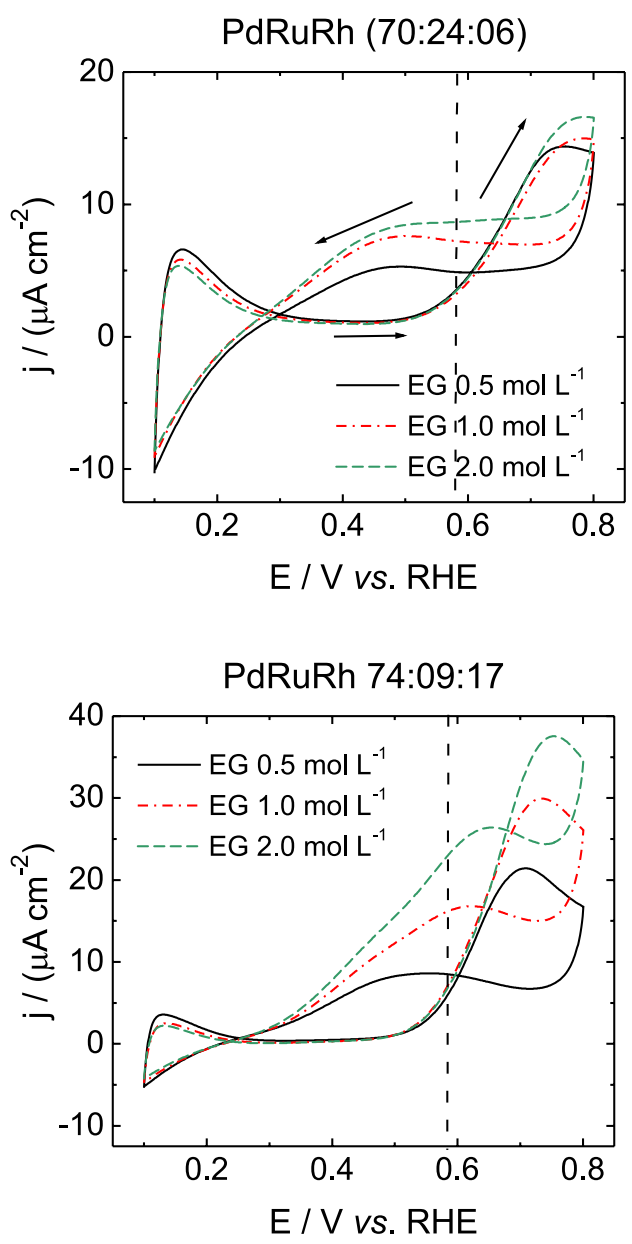
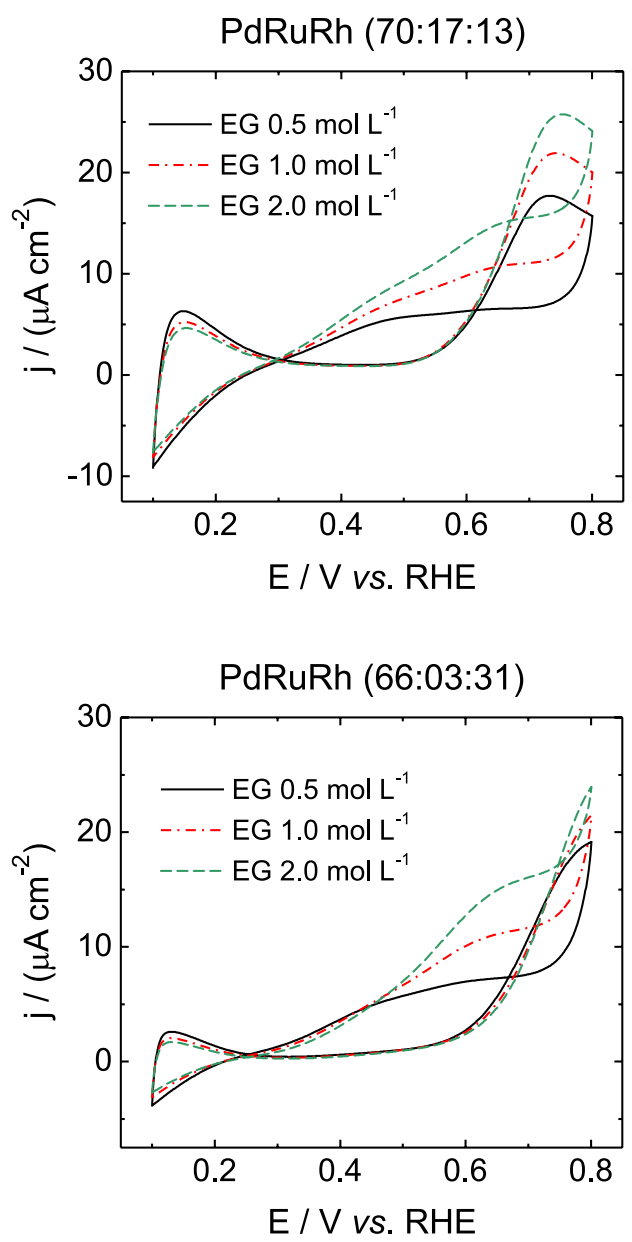

Figure 2. Cyclic voltammograms of PdRuRh electrodeposits in presence of different EG concentration at $0.02 \mathrm{~V} \mathrm{~s}^{-1}$. Real atomic compositions are indicated in the figure.

alcohol concentration within the entire range investigated). Such behavior suggests that the well-known ability of $\mathrm{Ru}$ to form oxygenated species could avoid the excess of organic fragments on the surface. This argument explains why PdRuRh 66:03:31 is more sensitive to the presence of EG, once in this case, the Ru content should be too low to cause the oxophilic effect.

When we take into account that during the operation of a typical fuel cell fed by alcohol concentrations of ca. $2.0 \mathrm{~mol} \mathrm{~L}^{-1}$ are required, the absence of self-inhibition effect demonstrated in Figure 4 can bring important implications for the development of systems fed with EG.

Now let us analyze the compromise between $\mathrm{Ru}$ and $\mathrm{Rh}$ compositions presented in Figures 2-4 from a molecular perspective by using in situ FTIR.

With the aim to elucidate the EG electrochemical behavior in acidic media in presence of PdRuRh electrocatalysts, in situ infrared spectroscopy experiments were performed under similar conditions to those applied in the collection of voltammograms, in presence of 0.5 and $2.0 \mathrm{~mol} \mathrm{~L}^{-1} \mathrm{EG}$.
The spectra were collect as a ratio $\left(R / R_{o}\right)$, where $R_{o}$ refers to initial spectra (background). In this configuration positive bands indicate the consumption of species, whereas negative bands indicated production of substances in $\mathrm{R}$ spectra, as previously discussed. ${ }^{28}$

Figure 5 shows a set of spectra obtained in presence of $0.1 \mathrm{~mol} \mathrm{~L}^{-1} \mathrm{HClO}_{4}+0.5 \mathrm{~mol} \mathrm{~L}^{-1}$ (top) or $2.0 \mathrm{~mol} \mathrm{~L}^{-1}$ (bottom) EG at PdRuRh electrodeposits containing 9, 17 and $24 \% \mathrm{Ru}$, along an increasing potential scan. On average, a spectrum was collected every $0.04 \mathrm{~V}$.

The analysis of the spectra shows the appearance of seven bands whose vibration modes are described in Table 1.

As the potential increases, we observe the production of $\mathrm{CO}_{2}$ above $0.5 \mathrm{~V}$, lower than on $\mathrm{Pt}(111)$ where $\mathrm{CO}_{2}$ starts from $0.6 \mathrm{~V} .{ }^{33}$ However, unlike what is observed for Pt surfaces, ${ }^{13,33}$ in this case there is no band associated to the presence of $\mathrm{CO}$. These results are similar to those observed by Wang et al. ${ }^{17}$ In this work, the authors studied the oxidation of EG on Pd pure surfaces at different $\mathrm{pHs}$, and noted the absence of $\mathrm{CO}$ formation in acid 


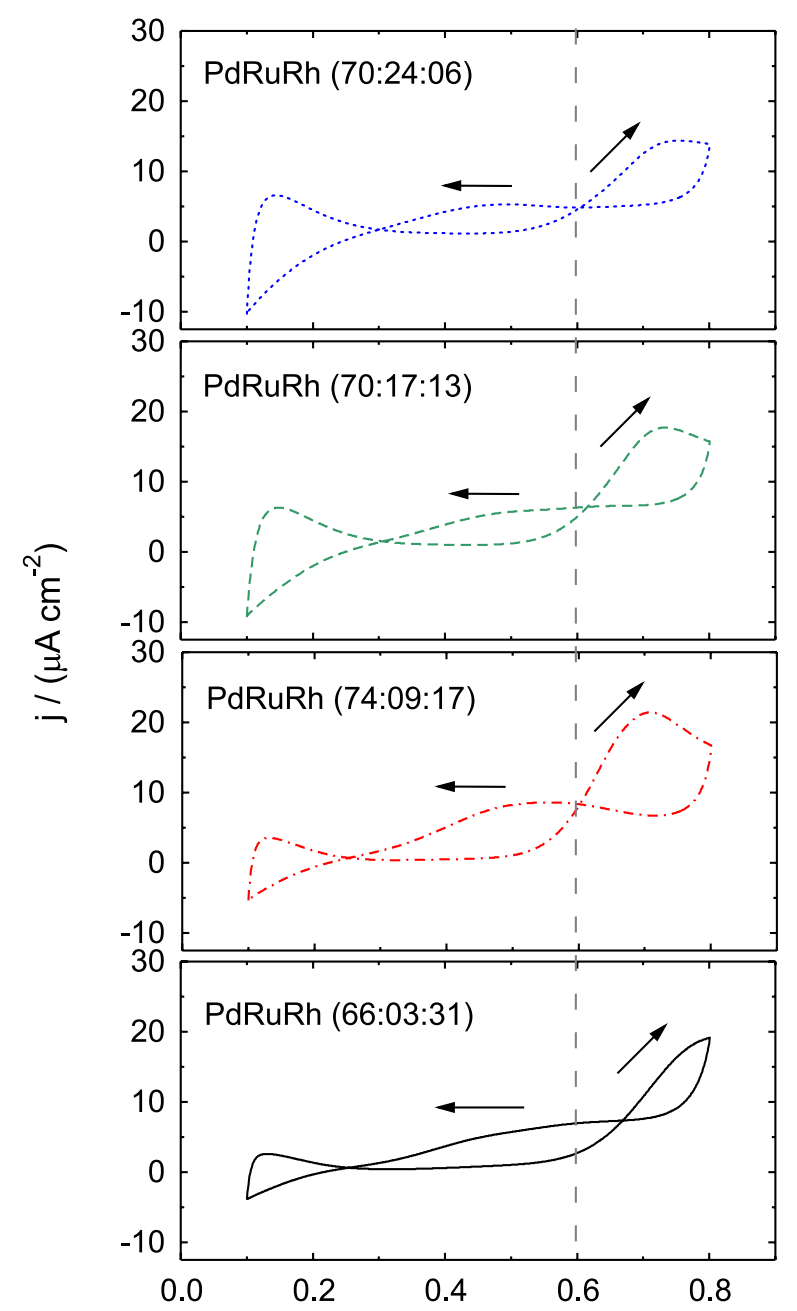

E / V vs. RHE

Figure 3. Cyclic voltammograms of PdRuRh electrodeposits in presence of $0.1 \mathrm{~mol} \mathrm{~L}^{-1} \mathrm{HClO}_{4}+\mathrm{EG} 0.5 \mathrm{~mol} \mathrm{~L}^{-1}$, at $0.02 \mathrm{~V} \mathrm{~s}^{-1}$. Real atomic compositions are indicated in the figure.

medium. ${ }^{17}$ According to the authors, these data suggest that the electro-oxidation of EG on Pt does not form $\mathrm{CO}$ as reaction intermediate or the oxidation of $\mathrm{CO}$ to $\mathrm{CO}_{2}$ is very fast, so that its surface coverage is always too low to be detected by FTIR. ${ }^{17}$ Regardless the exact nature of the phenomenon, this result is encouraging, since $\mathrm{CO}$ is considered a catalytic poison that harms the electrocatalysis of alcohols and its absence is a positive aspect. ${ }^{13,17}$

Another feature visible in spectra is the appearance of a positive band due to the exit of water from the thin layer $\left(1668 \mathrm{~cm}^{-1}\right)$. This phenomenon is explained by the volume occupied by $\mathrm{CO}_{2}$ which is produced at high potentials, and expels water from the thin layer formed between the electrode and the optical window. The band at $1115 \mathrm{~cm}^{-1}$ is due to the presence of $\mathrm{ClO}_{4}^{-}$, which enters the thin layer to maintain the electroneutrality of the solution, since the

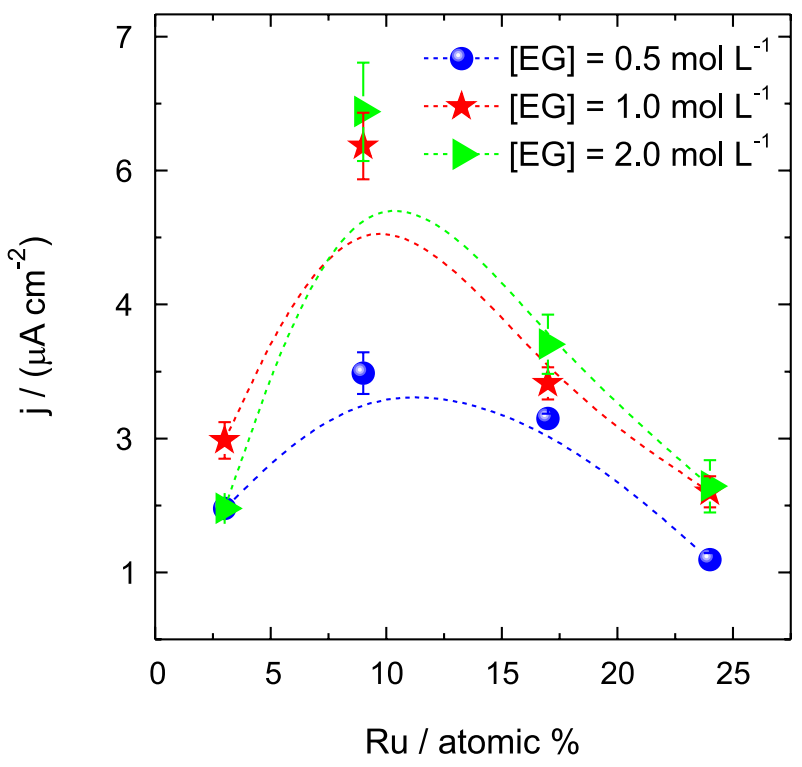

Figure 4. Current density obtained for PdRuRh electrodeposits after $1200 \mathrm{~s}$ of polarization at $0.6 \mathrm{~V}$ in presence of $0.1 \mathrm{~mol} \mathrm{~L}^{-1} \mathrm{HClO}_{4}+\mathrm{EG}$ : $0.5 \mathrm{~mol} \mathrm{~L}^{-1}$ (blue circle), $1.0 \mathrm{~mol} \mathrm{~L}^{-1}$ (red star) and $2.0 \mathrm{~mol} \mathrm{~L}^{-1}$ (green triangle). The standard deviations are indicated with vertical bars.

electro-oxidation of EG releases protons and causes an excess of positively charged species inside the thin layer. ${ }^{28,34}$

Other four bands, centered at 1350, 1287, 1235 and $1067 \mathrm{~cm}^{-1}$, evolve as the potential increases in presence of both EG concentrations. According to the literature, these bands are due to the formation of carboxylic acids, being formic acid, oxalic acid and glycolic acid already identified. ${ }^{17,35}$ These bands suggest a complex oxidation mechanism and for the discussion of the catalytic activities we will need to consider the corresponding oxidation processes, shown below:

$$
\begin{array}{r}
\mathrm{HO}-\mathrm{CH}_{2}-\mathrm{CH}_{2}-\mathrm{OH}+\mathrm{H}_{2} \mathrm{O} \rightarrow \underset{\text { glycolic acid }}{\mathrm{HO}-\mathrm{CH}_{2}-\mathrm{COOH}+4 \mathrm{H}^{+}+4 \mathrm{e}} \\
\text { gle }
\end{array}
$$

$\mathrm{HO}-\mathrm{CH}_{2}-\mathrm{CH}_{2}-\mathrm{OH}+2 \mathrm{H}_{2} \mathrm{O} \rightarrow 2 \mathrm{HCOOH}+6 \mathrm{H}^{+}+6 \mathrm{e}$

formic acid

$\underset{\text { oxalic acid }}{\mathrm{HO}-\mathrm{CH}_{2}-\mathrm{CH}_{2}-\mathrm{OH}+2 \mathrm{H}_{2} \mathrm{O} \rightarrow \underset{\text { (4) }}{\mathrm{HOOC}-\mathrm{COOH}}+8 \mathrm{H}^{+}+8 \mathrm{e}^{-}}$

$\mathrm{HO}-\mathrm{CH}_{2}-\mathrm{CH}_{2}-\mathrm{OH}+2 \mathrm{H}_{2} \mathrm{O} \rightarrow 2 \mathrm{CO}_{2}+10 \mathrm{H}^{+}+10 \mathrm{e}^{-}$

$\mathrm{CO}_{2}$

Pathways 2-5 refer to different degrees of oxidation of EG and involve different numbers of electrons. The complex mechanism is a good indication that the strong dependence of the catalytic activity with the composition of an electrocatalyst is related to its ability to promote certain oxidation pathways in particular over others. 

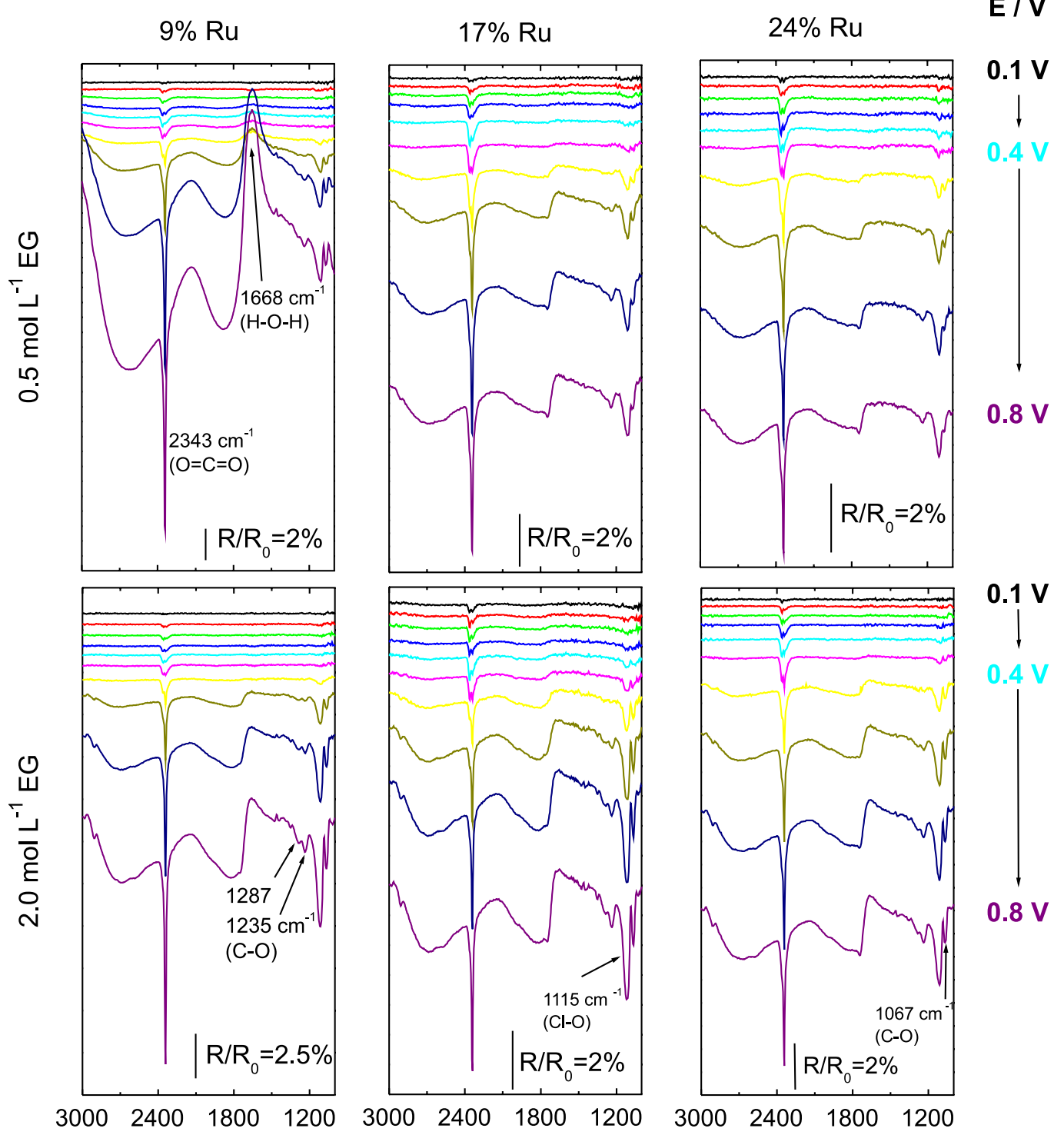

Wavenumber $/ \mathrm{cm}^{-1}$

Figure 5. In situ FTIR spectra obtained in $0.1 \mathrm{~mol} \mathrm{~L}^{-1} \mathrm{HClO}_{4}+0.5 \mathrm{~mol} \mathrm{~L}^{-1}$ (top) and $2.0 \mathrm{~mol} \mathrm{~L}^{-1}$ (bottom) EG for PdRuRh electrodeposits in different compositions. The spectra were normalized by equation 6 . Reference spectrum collected at $0.1 \mathrm{~V} v s$. RHE. Ru atomic percentage is indicated in the figure.

Table 1. Assignment of the main bands observed during the ethylene glycol electro-oxidation in acidic media

\begin{tabular}{lccc}
\hline Wavenumber $/ \mathrm{cm}^{-1}$ & Vibration mode & Chemical specie & Reference \\
\hline 2343 & stretch $\mathrm{O}=\mathrm{C}=\mathrm{O}$ & $\mathrm{CO}_{2}$ & 17 \\
1668 & water & 31 \\
1350 & stretch $\mathrm{O}-\mathrm{C}-\mathrm{O}$ & formate or formic acid & 17 \\
& & bridge-bonded oxalate & 32 \\
1287 & stretch C-O & glycolic acid or oxalic & 13 \\
1235 & stretch C-O & carboxilic acid & 13 \\
1115 & stretch Cl-O & perchlorate & 17 \\
1067 & stretch $\mathrm{C}-\mathrm{O}$ & oxalic acid & 17 \\
\hline
\end{tabular}

Aiming to establish this correlation, we try to integrate the bands related to oxidation products as a function of applied potential and the concentration of
EG. Unfortunately, as shown in Figure 5, the range of wavenumber between 1350 and $1235 \mathrm{~cm}^{-1}$ shows a series of bands partially overlapped, hence is difficult to establish a 
baseline, and those bands related to the formation of formic acid and glycolic acid could not be analyzed quantitatively.

On the other hand, the band related to the formation of oxalic acid $\left(1067 \mathrm{~cm}^{-1}\right)$ is comparatively intense and appears in a region of the spectrum where is possible to determine a baseline, as well as the band related to the formation of $\mathrm{CO}_{2}\left(2343 \mathrm{~cm}^{-1}\right)$. Thus, an analysis of the absorbance of these two species could be made depending on the applied potential and the concentration of EG. Here it is important to note that the results of the different compositions cannot be directly compared by this procedure, due to their different electroactive areas. The results for the compositions containing 09,17 and $24 \%$ Ru are shown in Figure 6 . The composition containing $3 \%$ of Ru presented the worst catalytic response among those investigated and will be not analyzed by FTIR.

An interesting aspect of Figure 6 is that the $\mathrm{CO}_{2}$ production seems to begin before than oxalic acid for all compositions studied, in clear opposition to the behavior observed by Wang et al. ${ }^{17}$ for pure Pd. Furthermore, the formation of oxalic acid started earlier than on $\operatorname{Pt}(111) .^{33}$ From the analysis of the absorbance of oxalic acid (left column), we also realize that the compositions containing less $\mathrm{Ru}$ are less sensitive to the alcohol concentration. The oxalic acid production is very similar to $09 \% \mathrm{Ru}$ at both EG concentrations, whereas is favored for 17 and $24 \%$ $\mathrm{Ru}$ in presence of $2.0 \mathrm{~mol} \mathrm{~L}^{-1} \mathrm{EG}$. On the other hand, the production of $\mathrm{CO}_{2}$ is not significantly affected by the concentration of EG, regardless the composition. This result helps to understand some of the results of Figure 3. Specifically, the results of Figure 6 indicate that for a given composition when the concentration of EG increases from 0.5 to $2.0 \mathrm{~mol} \mathrm{~L}^{-1}$, the gain in current densities may be due to a higher production of oxalic acid. However, the results do not explain why the composition containing $09 \% \mathrm{Ru}$ is the most active towards EG electro-oxidation, once the data between the various catalysts cannot be quantitatively compared with each other.

Due to this difficulty, we decided to use a new experimental approach. Before beginning the experiments

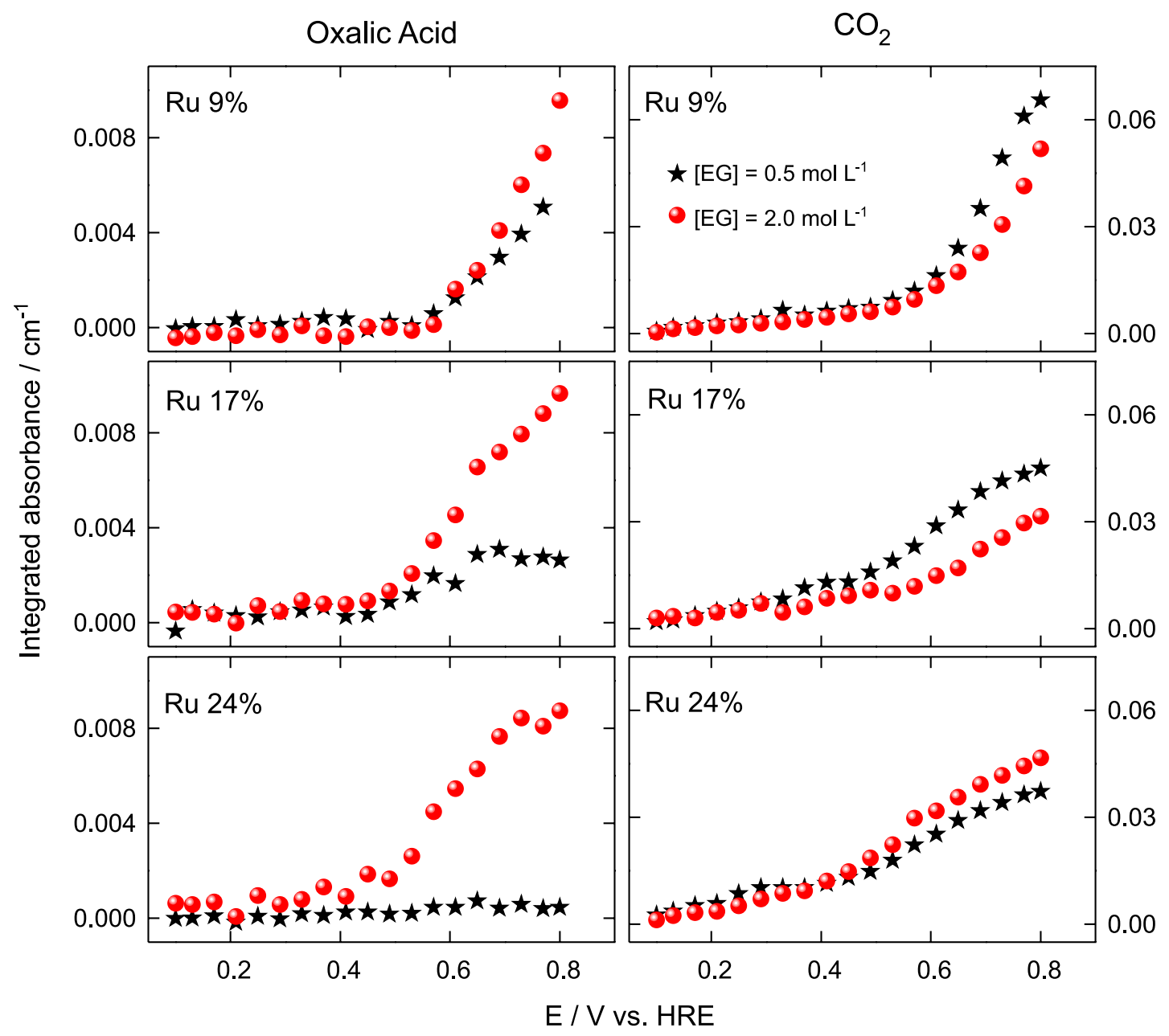

Figure 6. Integrated absorbance for oxalic acid (left column) and $\mathrm{CO}_{2}$ (right column) as a function of potential for concentrations of 0.5 mol $\mathrm{L}^{-1}$ (black star) and $2.0 \mathrm{~mol} \mathrm{~L}^{-1}$ (red circle) EG obtained from the in situ FTIR spectra as showed in Figure 4. Ru atomic \% is indicated in the figure. 
with EG, a CO monolayer was adsorbed on the electrodeposits surface at $0.05 \mathrm{~V}$ and then oxidized through a potential step to $0.8 \mathrm{~V}$. While this potential was kept constant, successive spectra were collected in order to observe the maximum absorbance of $\mathrm{CO}_{2}$. Similar to the procedure performed during the oxidative removal of $\mathrm{CO}$ (CO stripping), this experiment allowed the determination of the normalization parameter called maximum absorbance of $\mathrm{CO}_{2}\left(\mathrm{~A}_{\mathrm{CO}_{2, \max }}\right)$. Once determined for each electrodeposit, this parameter was used for the normalization of the spectra $\mathrm{R}$ by using the equation below:

$$
\mathrm{R}^{\prime}=100 \times\left(\mathrm{R} / \mathrm{A}_{\mathrm{CO}_{2, \text { max }}}\right)
$$

The normalization parameter considers the electroative area of each catalyst, since the $\mathrm{CO}_{2}$ absorbance is a function of it. Thus, the use of equation 6 allows the spectra of different materials investigated to be directly compared. The spectra of Figure 7 illustrate the comparison of electrodeposits, containing from 03 to $24 \% \mathrm{Ru}$, obtained at $0.8 \mathrm{~V}$ in the presence of $2.0 \mathrm{M} \mathrm{EG}$.

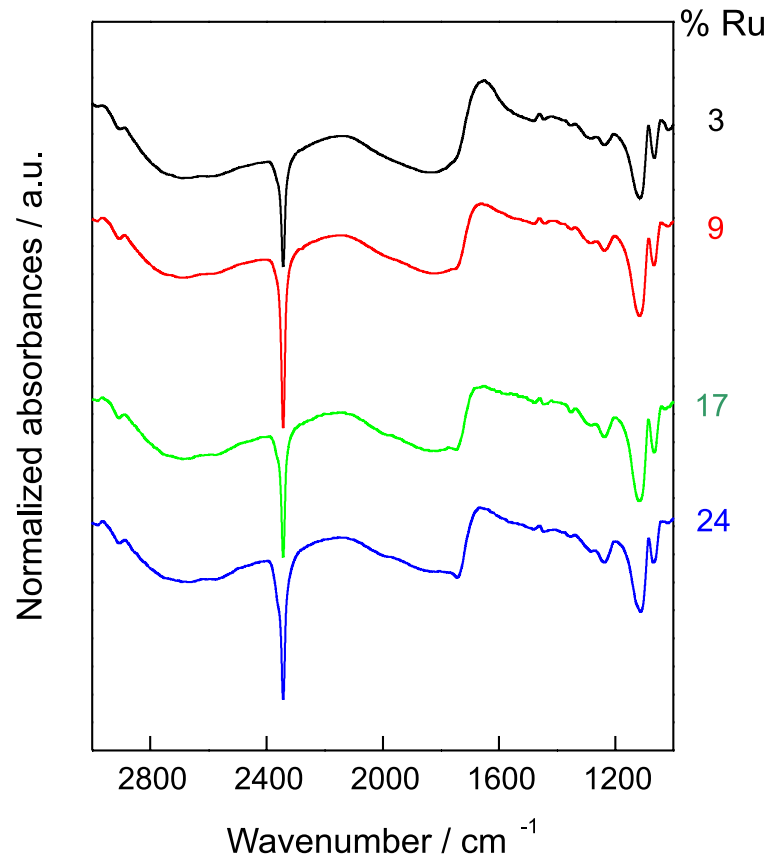

Figure 7. In situ FTIR spectra obtained in $0.1 \mathrm{~mol} \mathrm{~L}^{-1} \mathrm{HClO}_{4}+2.0 \mathrm{~mol} \mathrm{~L}^{-1}$ EG for PdRuRh electrodeposists in different compositions. The spectra were normalized by equation 6 . Reference spectrum collected at $0.1 \mathrm{~V} v s$. RHE.

Figure 7 helps us to understand the main features of Figures 2 and 3. After normalized by the respective maximum absorbance of $\mathrm{CO}_{2}$, the magnitudes of the bands are similar for all compositions, except for $\mathrm{CO}_{2}$. Specifically concerning this band, Figure 7 shows that PdRuRh 74:09:17 (red curve, $9 \% \mathrm{Ru}$ ) shows a $\mathrm{CO}_{2}$ signal significantly higher than those of the other compositions, indicating that this composition is more active for the formation of $\mathrm{CO}_{2}$. Now, considering that the $\mathrm{CO}_{2}$ oxidation pathway is the one that involves more electrons (see equations 2-5), it is expected that the surface which forms more $\mathrm{CO}_{2}$ is responsible for the higher current densities.

Data in Figure 7 are of great importance because they suggest that PdRuRh 74:09:17 not only has the best electrocatalytic activity, it is also the composition more selective to the production of $\mathrm{CO}_{2}$, which is the desired oxidation pathway in the case of low temperature fuel cells fed by alcohols.

\section{Conclusions}

Ethylene glycol electro-oxidation is sensitive to the composition of ternary PdRuRh electrocatalysts. Electrochemical results show that PdRuRh 74:09:17 presents the best catalytic activity towards ethylene glycol electro-oxidation. Although there is some dependence between the current densities and the concentration of the alcohol, it was not observed the self-inhibitory effect reported for platinum surfaces, which indicates a good tolerance of PdRuRh to the presence of ethylene glycol. In situ FTIR results indicate that the electro-oxidation of EG involves a complex mechanism, with the formation of various products of oxidation such as glycolic acid, oxalic acid, formic acid and carbon dioxide. The spectroscopic results allow us to understand why PdRuRh 74:09:17 presents the best electrocatalytic activity in terms of an increased production of $\mathrm{CO}_{2}$.

\section{Acknowledgments}

The authors acknowledge financial assistance from CAPES, CNPq (Grants No. 405695/2013-6 and 309176/2015-8), FUNDECT and FINEP. G. A. B. M. and P. H. B. F. are indebted to CAPES for post-graduation fellowships.

\section{References}

1. Griffin, M. B.; Rodrigues, A. A.; Montemore, M. M.; Monnier, J. R.; Williams, C. T.; Medlin, J. W.; J. Catal. 2013, 307, 111.

2. Matsuoka, K.; Inaba, M.; Iriyama, Y.; Abe, T.; Ogumi, Z.; Matsuoka, M.; Fuel Cells 2002, 2, 35.

3. Livshits, V.; Peled, E.; J. Power Sources 2006, 161, 1187.

4. Hahn, F.; Beden, B.; Kadirgan, F.; Lamy, C.; J. Electroanal. Chem. 1987, 216, 169.

5. El-Shafei, A. A.; El-Maksoud, S. A. A.; Fouda, A. S.; J. Electroanal. Chem. 1995, 395, 181. 
6. Maxakato, N. W.; Arendse, C. J.; Ozoemena, K. I.; Electrochem. Commun. 2009, 11, 534.

7. Wieland, B.; Lancaster, J. P.; Hoaglund, C. S.; Holota, P.; Tornquist, W. J.; Langmuir 1996, 12, 2594.

8. Dalbay, N.; Kadirgan, F.; Electrochim. Acta 1991, 36, 353.

9. BeŁTowska-Brzezinska, M.; ŁUczak, T.; Holze, R.; J. Appl. Electrochem. 1997, 27, 999.

10. Demarconnay, L.; Brimaud, S.; Coutanceau, C.; Léger, J. M.; J. Electroanal. Chem. 2007, 601, 169.

11. Fan, Y.-J.; Zhou, Z.-Y.; Zhen, C.-H.; Fan, C.-J.; Sun, S.-G.; Electrochim. Acta 2004, 49, 4659.

12. Sun, S.-G.; Chen, A.-C.; Electrochim. Acta 1994, 39, 969.

13. de Lima, R. B.; Paganin, V.; Iwasita, T.; Vielstich, W.; Electrochim. Acta 2003, 49, 85.

14. Habibi, E.; Bidad, E.; Feizbakhsh, A.; Fazli, M.; Int. J. Hydrogen Energy 2014, 39, 18416.

15. He, G.; Song, Y.; Kang, X.; Chen, S.; Electrochim. Acta 2013 , 94, 98.

16. Mao, H.; Wang, L.; Zhu, P.; Xu, Q.; Li, Q.; Int. J. Hydrogen Energy 2014, 39, 17583.

17. Wang, L.; Meng, H.; Shen, P. K.; Bianchini, C.; Vizza, F.; Wei, Z.; Phys. Chem. Chem. Phys. 2011, 13, 2667.

18. Giz, M. J.; Camara, G. A.; Maia, G.; Electrochem. Commun. 2009, 11, 1586 .

19. Camara, G. A.; de Lima, R. B.; Iwasita, T.; J. Electroanal. Chem. 2005, 585, 128.

20. Camara, G. A.; de Lima, R. B.; Iwasita, T.; Electrochem. Commun. 2004, 6, 812.

21. Mavrikakis, M.; Hammer, B.; Norskov, J. K.; Phys. Rev. Lett. 1998, 81, 2819.
22. Greeley, J.; Mavrikakis, M.; Catal. Today 2006, 111, 52.

23. Mello, G. A. B.; Giz, M. J.; Camara, G. A.; Crisci, A.; Chatenet, A.; J. Electroanal. Chem. 2011, 660, 85.

24. Leão, E. P.; Giz, M. J.; Camara, G. A.; Maia, G.; Electrochim. Acta 2011, 56, 1337.

25. Falase, A.; Garcia, K.; Lau, C.; Atanassov, P.; Electrochem. Commun. 2011, 13, 1488.

26. Schnaidt, J.; Heinen, M.; Jusys, Z.; Behm, R. J.; Catal. Today 2013, 202, 154.

27. Lin, J.-L.; Ren, J.; Tian, N.; Zhou, Z.-Y.; Sun, S.-G.; J. Electroanal. Chem. 2013, 688, 165.

28. Iwasita, T.; Nart, F. C.; Prog. Surf. Sci. 1997, 55, 271.

29. Camara, G. A.; Iwasita, T.; J. Electroanal. Chem. 2005, 578, 315.

30. Gomes, J. F.; Martins, C. A.; Giz, M. J.; Tremiliosi-Filho, G.; Camara, G. A.; J. Catal. 2013, 301, 154.

31. Iwasita, T.; Xia, X.; J. Electroanal. Chem. 1996, 411, 95.

32. Berná, A.; Rodes, A.; Feliu, J. M.; Electrochim. Acta 2004, 49, 1257.

33. Arán-Ais, R. M.; Herrero, E.; Feliu, J. M.; Electrochem. Commun. 2014, 45, 40.

34. Li, M.; Cullen, D. A.; Sasaki, K.; Marinkovic, N. S.; More, K.; Adzic, R. R.; J. Am. Chem. Soc. 2013, 135, 132.

35. Freitas, R. G.; Antunes, E. P.; Christensen, P. A.; Pereira, E. C.; J. Power Sources 2012, 214, 351.

Submitted: July 18, 2016 Published online: October 5, 2016 